This item was submitted to Loughborough's Research Repository by the author.

Items in Figshare are protected by copyright, with all rights reserved, unless otherwise indicated.

\title{
Real time energy management system for smart buildings to minimize the electricity bill
}

PLEASE CITE THE PUBLISHED VERSION

https://doi.org/10.1515/ijeeps-2016-0238

\section{PUBLISHER}

(c) Walter de Gruyter $\mathrm{GmbH}$

VERSION

AM (Accepted Manuscript)

\section{PUBLISHER STATEMENT}

This work is made available according to the conditions of the Creative Commons Attribution-NonCommercialNoDerivatives 4.0 International (CC BY-NC-ND 4.0) licence. Full details of this licence are available at: https://creativecommons.org/licenses/by-nc-nd/4.0/

\section{LICENCE}

CC BY-NC-ND 4.0

\section{REPOSITORY RECORD}

Chauhan, Rajeev Kumar, Bharat Singh Rajpurohit, Lingfeng Wang, Francisco M. Gonzalez-Longatt, and S.N. Singh. 2019. "Real Time Energy Management System for Smart Buildings to Minimize the Electricity Bill". figshare. https://hdl.handle.net/2134/26977. 


\title{
Real Time Energy Management System for Smart Buildings to Minimize the Electricity Bill
}

\author{
R. K. Chauhan, Senior Member, IEEE, B. S. Rajpurohit, Senior Member, IEEE, L. Wang, Senior \\ Member, IEEE, F. M. Gonzalez-Longatt, Senior Member, IEEE, S.N. Singh, Senior Member, IEEE
}

\begin{abstract}
This paper presents a real time price based energy management system for DC microgrid. The DC distribution system is considered as a prospective system according to the increase of DC loads and DC output type distribution energy resources (DERs) such as photovoltaic (PV) systems, battery bank (BB), hybrid car (HC) and fuel cells. The control objective is to achieve the optimal cost of energy. The proposed control scheme is developed based on the source as well as load scheduling of the DC microgrid. The source scheduling algorithm is based on the selection of cheapest power source to supply the load of DC microgrid and achieve the optimal electricity price. The BB and HC charges in regular hours at the less electricity price to supply the future load during the high electricity price of grid. The load scheduling algorithm shift the deferrable load of the building from peak to the regular hours to obtain the lower cost of energy for building. The proposed scheme significantly decreases peak demand, which is main cause of load shedding. Dynamic simulation is presented to access the control performance with price fluctuations and robustness of the system.
\end{abstract}

Index Terms-DC microgrid, PV generator, distributed generation, load and source management, smart building, critical load.

\section{INTRODUCTION}

$\mathrm{T}$ he control of the power quality becomes the big challenge, as there are too much fluctuation in the grid power and voltage because of the stochastic nature of the PV output power. The distributed generators (DGs) are the solution of these kinds of disturbances and fluctuations. DGs have many functions such as instantaneous reserve [1], emergency supply, and pinnacle saving [2]. The services of DGs are such that they have the ability to power control of photovoltaic (PV) generators [3]. The electricity generation, based on distributed energy sources (DERs) such as PV, and the wind are not controllable because they depend on environmental conditions [4]. The power fluctuation in DC microgrid due to penetration of the DERs imposes to introduces the integration of the battery bank (BB) and capacitors with the

R. K. Chauhan and B. S. Rajpurohit are with School of Computing and Electrical Engineering, Indian Institute of Technology Mandi, India. (e-mail: rajeevchr_nitj@yahoo.com; bsr@iitmandi.ac.in)

L. Wang is with the Department of Electrical Engineering at the University of Wisconsin, Milwaukee, USA. (e-mail: wang289@uwm.edu)

F. M. Gonzalez-Longatt is with Electrical and Systems Engineering, Loughborough University, UK. (f.gonzalez-longatt@lboro.ac.uk)

S. N. Singh is with Department of Electrical Engineering, Indian Institute of Technology Kanpur, India. (e-mail: snsingh@iitk.ac.in)
DERs and loads to improve the power quality and reliability of the system. The significant development in DC microgrid increased the utilization of $\mathrm{BB}$ and electric vehicle (EV) as electric energy storage (ES) devices in the DC microgrid. A proper management of minimal utilization of the ES and maximum utilization of the PV can be able to decrease the electricity cost for the consumers. The benefits and cost efficiency of EV depend on the charging activities of EV [5]. The decentralized methods for EV charging are based on electricity auction [9], dual tariffs from the owner of EV in different regions, and sharing of energy cost [10]. The Dual tariff scheme is suitable only if there is no share of EV generation publically [11]. In centralized coordination method, the utility is used to charge the EV directly in consideration with the grid balancing and indirectly keeping the EV owners benefits in term to stop the charging in the peak hours. The time and rate of EV charging is decided by an aggregator [13]. It also acts as an interface between the EV and grid operator [14]. It provides the charging for considering the benefits on both sides i.e. on the grid as well as consumer side or EV owner side [15].

On the other hand the demand side management (DSM) can change the use of load quantitatively by implementation and planning for the utility or monitoring the consumer activities of load utilization. Load management and consumer side local generation are other tasks of the DSMs [16]. The DSM schemes are employed to use the available energy efficiently without installing new generation, transmission infrastructure [17]. The decentralised DSM mechanism to defragment of home loads is based on grid prices and utility companies offers the incentives to use the devices optimally [18 ]. The heuristic based evolutionary algorithm is used for day-ahead load shifting to reduce the peak demand and reshape the demand curve [19]. The DSM promotes distributed generation in order to avoid long-distance transport. The DSM facilitates the consumption of locally generated energy immediately whenever it is available for local loads [20]. The main advantage of DSM's, is that it has less expensive nature to intelligently influence a load, have the ability to build a new power plant or install some electric storage device [21].

In this paper a real-time electricity price based energy management (RTEPEM) system has been proposed for buildings. The RTEPEM is based on the management of both, source and load. The idea behind the optimization is: (a) the source management; by shifting the load from one source to other source as well getting the benefit of stored energy in the 
$\mathrm{BB}$ and hybrid car $(\mathrm{HC})$ to get the minimum cost of energy, (b) load management; by scheduling there operating time of the deferrable load according to the consumer priority from peak hours to the regular hours.

In this paper two types of load control schemes has been consider in the building for comparative analysis; (a) Traditional control i.e. manual control (MC) scheme; the building appliances are controlled manually, (b) Automation control (AC) scheme; the building appliances are controlled automatically by supervisory control and data acquisition (SCADA) system. The building load are classified in two category (a) critical load (CL) such as fan, light etc. (b) non critical load (NCL) such as water pump, washing machine etc. On performing simulation it is proved that in case of automation control scheme, the energy cost, and peak demand are significantly decrease as compared with traditional control for the loads..

In this paper, the description of a building configuration is explained in section II. The control parameters and action of the appliances are discussed in section III. A formulation is developed for the DC microgrid electricity sale price optimization in section IV. The obtained results from simulation are discussed in section $\mathrm{V}$ and the outcomes from the research are concluded in section VI.

\section{SYSTEM CONFIGURATION}

\section{A. Layout of DC Microgrid}

The schematic layout of the DC microgrid connected to PU, and distributed energy resources (DERs) included with DC building is shown in Fig.1. The loads are connected to the control room of the DC microgrid via smart sensors. The computerized control of appliances and DERs has been set up to respond to the electricity price of the DC microgrid. In the proposed RTEPEM system the consumer has to minimize their energy use in the time interval when the DC microgrid is under stress (i.e. high electricity price) due to high demand and low generation. It shifts some of their power use to the time interval when the DC microgrid is less stressed and the electricity price is low. It helps to reduce the DC microgrid stress, electricity price and electricity bill of the building as well.

The proposed RTEPEM system renders the caliber to automatic turn 'ON/OFF' the appliances and keeps the track of the power sharing of PU, DER and use of energy of specific appliances such as tracking the energy use of the air conditioner, refrigerator, and geyser. The level sensor LS-1 and LS-2 are used to measure the water level in the main tank and water purifier tank. The temperature sensors (TS-1, and TS-2) are installed to measure temperature in the bedroom and living room respectively. The proximity sensors (PS-1, PS-2, PS-3, PS-4, PS-5 and PS-6) are used to detect the human presence in all the room excluding garage in the building. The control room consists of the remote terminal unit (RTU) and computer (SCADA system). The computer and RTU are connected via a RS-232 cable while the RTU is connected to the sensors and the electronics switches via a wireless network. The RTU collect the data from the smart sensors and send it to the control station. RTU also send the control single to activate the actuators to switch 'ON/OFF' the appliances. The power electronics interface (PES-1, PES-2, PES-3, PES-4 and PES-5) for DER has the ability to control the power disturbance in the DC microgrid. The power balance in the DC bus is balanced by power electronic switches (PESs) of PV panel-1, PV panel-2 and the PES of public utility. The BB and hybrid car (HC) improves the power quality by storing and the releasing the power to the DC bus. They also improve the reliability of the DC microgrid in the absence of the PV and PU.

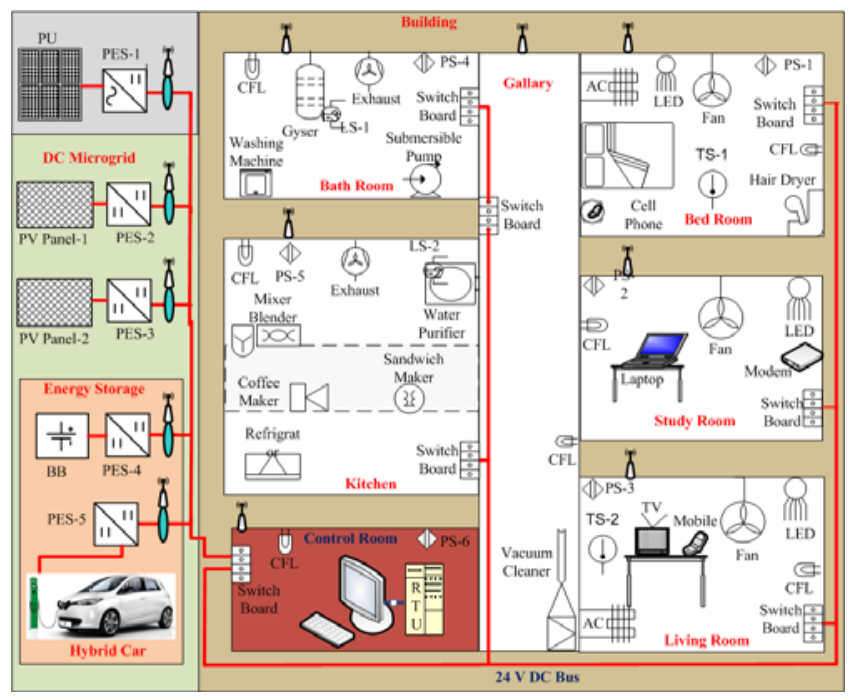

Fig. 1. Layout of DC microgrid for building.

\section{B. DC Microgrid Price}

The DC microgrid building is fed by the PV, PU and storage devices (BB and $\mathrm{HC}$ ). The electricity prices of the PV, $\mathrm{BB}, \mathrm{HC}$ are considered static and different for each power source. The PV electricity sale price is calculated as Rs. 3.82 with the consideration of the capital cost Rs.1, 00,0 00, life time of 20 years including with 300 sunny days. The round trip efficiency of the batteries is $85 \%$. The electricity price of PU varies with respect to time and most of the time it remains higher than the PV prices as shown in Fig.2. The BB and HC charging price are considered as Rs. 3.82 per $\mathrm{kWh}$. The discharging price is the function of charging price and its own efficiency and calculated as Rs. 4.39 per $\mathrm{kWh}$. The $\mathrm{HC}$ is partial charged by the fuel generator of the $\mathrm{HC}$ so the electricity sale price of $\mathrm{HC}$ is Rs. 4.447 per $\mathrm{kWh}$. The PV electricity sale prices are the lowest out of the entire power sources for the considered DC microgrid. So the PV power always fed to the DC microgrid without considering the electricity price of the DC microgrid.

The power sharing of the $\mathrm{HC}, \mathrm{BB}$ and the $\mathrm{PU}$ is depended on the electricity price of the DC microgrid. The $\mathrm{HC}$ and $\mathrm{BB}$ start power feeding to the DC microgrid as the DC microgrid price is higher than the Rs. $4.39 / \mathrm{kWh}$ and Rs. $4.477 / \mathrm{kWh}$ respectively. While the $\mathrm{HC}$ and $\mathrm{BB}$ start charging as the electricity sale price in the DC microgrid is lower or equal to the Rs. 3.82/kWh. Similarly, the DC microgrid starts power 
fed to the PU, as the PU prices are higher than the DC microgrid price and start consumption if the PU prices are lower than the DC microgrid price.

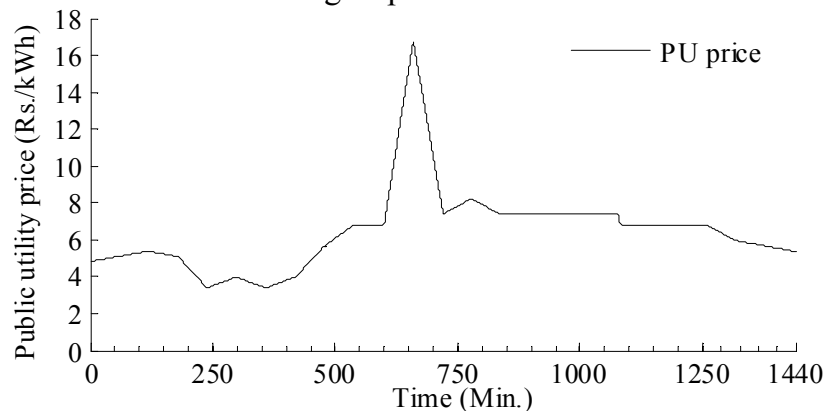

Fig. 2. Public utility prices for a typical day

The real-time electricity price of the DC microgrid is the function of source power sharing with DC microgrid and the electricity sale price of source at each time instant. Therefore the DC microgrid electricity price can be expressed as:

$$
\zeta_{m}(t)=\frac{\sum_{j=1}^{n_{p}} E_{j}(t) \zeta_{j}(t)}{\sum_{j=1}^{n_{p}} E_{j}(t)}
$$

where $\zeta_{m}(t)$ is the real-time electricity price of the DC microgrid at time instant $t, n_{p}$ is the number of the power source, $E j(t)$ is the specific energy ( $\mathrm{kwh} /$ minute) feed-in by $j^{\text {th }}$ source, $\zeta_{j}(t)$ is the energy cost for $1 \mathrm{kWh}$ energy for the $j^{t h}$ source.

\section{Power Sources}

PV Generator: The output power of PV plant is mainly depends on the irradiance level, and ambient temperature. The output power of the PV plant at the maximum power point (MPP) can be expressed as [15]:

$$
P_{p v}=\left[P_{p v s t} \times \frac{G_{i r s t}}{1000} \times\left\{1-\alpha_{s t}\left(T_{c}-25\right)\right\} \times N_{p v s} \times N_{p v p}\right]
$$

where $P_{p v}$ is the output power of PV plant at MPP, $P_{p v s t}$ is the rated PV power at the MPP with standard test condition (STC), $G_{i r s t}$ is the irradiance level at STC, $\alpha_{s t}$ is the power temperature coefficient at MPP, $T_{c}$ is the PV cell temperature, $N_{p v s}$ and $N_{p v p}$ are the number of modules in series and parallel the composed the PV plant.

Public Utility: The PU is the power source for the DC microgrid. The PU can act as a source as well as load. If the PU acts as source then the PU power $\left(P_{g s}\right)$ can be expressed as:

$$
P_{g s}^{s}(t)=\left\{\begin{array}{l}
\sum_{\substack{k=1 \\
y=1 \\
n_{d g}, n_{a}}}^{n_{d s}, n_{a}} P_{d s k}^{s}(t)-P_{L y}^{S}(t) ; \text { if } \zeta_{s x}^{\prime}(t)<\zeta_{g}(t) \\
\sum_{\substack{k=1 \\
y=1}}^{s} P_{d g k}^{s}(t)-P_{L y}^{s}(t) ; \text { if } \zeta_{s x}^{\prime}(t)>\zeta_{g}(t) \\
\sum_{\substack{d g \\
n_{d g}, n_{m}}} P_{d g k}^{s}(t)-P_{L y}^{s}(t) ; \text { if } \zeta_{s x}(t) \geq \zeta_{g}(t)
\end{array}\right.
$$

where $\zeta_{s x}^{\prime}$, and $\zeta_{s x}$ are the sale and buy electricity prices of $x^{\text {th }}$ ES. The $\zeta_{g}$ is the electricity sale price for PU. The $P_{L}, P_{d g}$, and $P_{d s}$ are the powers of load, distributed generator and distributed sources respectively. $n_{d s}$ and $n_{d g}$ are the numbers of distributed source and distributed generator (PV panels). $n_{a}$ are the number of appliances in the microgird, $n_{m}$ are the number of load (appliance and ES) connected to the microgird $\left(\mathrm{n}_{\mathrm{m}}=\mathrm{n}_{\mathrm{a}}+\mathrm{n}_{\mathrm{es}}\right), n_{e s}$ is the number of gradable ES (BB and HC).

If the PU acts as load then the PU power $\left(P_{g l}\right)$ can be expressed as:

$$
P_{g l}^{s}(t)=\left\{\begin{array}{l}
\sum_{\substack{k=1 \\
y=1 \\
n_{d g}, n_{a}}}^{n_{d s}, n_{a}} P_{d s k}^{S}(t)-P_{L y}^{s}(t) ; \text { if } \zeta_{g}(t) \geq \zeta_{s x}^{\prime}(t) \\
\sum_{\substack{k=1 \\
y=1}}^{n_{d g}, n_{m}} P_{d g k}^{s}(t)-P_{L y}^{s}(t) ; \text { if } \zeta_{s x}(t)<\zeta_{g}(t)<\zeta_{s x}^{\prime}(t) \\
\sum_{\substack{k=1 \\
y=1}}^{S} P_{d g k}(t)-P_{L y}^{s}(t) ; \text { if } \zeta_{s x}(t) \geq \zeta_{g}(t)
\end{array}\right.
$$

The ES can act as a load if the PV generation is greater than the loads of the building or the PU prices is less than the ES buying price $\left(\zeta_{s x}\right)$. The $x^{\text {th }}$ ES power $\left(P_{s x}\right)$ can be expressed as:

$$
P_{s x}^{s}(t)= \begin{cases}\sum_{k=1}^{n_{d g}, n_{m}-1}\left[P_{d g k}^{S}(t)-P_{m y}^{S}(t)\right] ; & \text { if } \Delta P_{e}<P_{s x r} \text { and } \\ y=1 & \zeta_{m}(t) \leq \zeta_{s x}(t) \\ P_{s x r}^{s}(t) ; & \text { if } \Delta P_{e} \geq P_{s x x} \text { and } \\ \zeta_{g}(t)<\zeta_{m}(t) \leq \zeta_{s x}(t)\end{cases}
$$

where $P_{s x}$ and $P_{s x r}$ are the measured charging and reference charging powers of $x^{\text {th }} \mathrm{ES}, P_{m y}$ is the power consumption in $y^{\text {th }}$ load of the DC microgrid in $s$ scenario.

The reference charging power of the $x^{\text {th }}$ ES can be expressed as:

$P_{s x r}^{s}(t)=\left(1-\frac{\psi_{s x}(t)}{100}\right) \mu_{s x} V_{s x}$

where $\mu_{s x}$ is power rating of $x^{\text {th }} \mathrm{ES}, V_{s x}$ is the terminal voltage of $x^{\text {th }}$ ES and $\psi_{s x}$ is the state of charge (SOC) at time instant $t$. The SOC is the ratio of its present capacity $(\mu(t))$ to the nominal capacity $\left(\mu_{n}\right)[22]$. The SOC can be defined as:

$\psi_{s x}(t)=\frac{\mu(t)}{\mu_{n}}$ 
The $\Delta P_{e}$ is the difference of sum of $\left(n_{m}-1\right)$ loads power (appliance and ES in s scenario) and sum of DGs output power. The $\Delta P_{e}$ can be expressed as:

$$
\Delta P_{e}=\sum_{\substack{k=1 \\ y=1}}^{n_{d s}-1, n_{m}}\left[P_{d g k}^{s}(t)-P_{m y}^{s}(t)\right]
$$

The ES behaves as source for the following conditions:

$$
P_{s L x}^{s}(t)= \begin{cases}\sum_{k=1}^{n_{d s}-1, n_{a}}\left[P_{d s k}^{s}(t)-P_{m y}^{s}(t)\right] ; & \text { if } \Delta P_{e L}<P_{s L L} \text { and } \\ \zeta_{g}(t)>\zeta_{s x}(t) \\ P_{s x L r}^{s}(t) ; & \text { if } \Delta P_{e L} \geq P_{s x L r} \text { and } \\ \zeta_{g}(t)>\zeta_{s x}^{\prime}(t)\end{cases}
$$

where $P_{s L x}$ and $P_{s x L r}$ are the load demand and rated discharging reference power of $x^{\text {th }} \mathrm{ES}, P_{d s k}$ is the $x^{\text {th }} \mathrm{ES}$ current, $\zeta_{s x}^{\prime}$ is the sale price of $x^{t h}$ ES. The $\Delta P_{e L}$ is the difference of output power of all $\left(\mathrm{n}_{\mathrm{ds}}-1\right)$ power source and building load demand and can be expressed as:

$$
\Delta P_{e L}=\sum_{\substack{k=1 \\ y=1}}^{n_{d s}-1, n_{a}}\left[P_{d s k}^{s}(t)-P_{L y}^{s}(t)\right]
$$

The ES (as source) rated discharging reference power $\left(P_{s x L r}\right)$ can be expressed as:

$P_{s x L r}^{s}(t)=\left(\frac{\psi_{s x}(t)}{100}\right) \mu_{s x} V_{s x}$

\section{Building Load}

The appliances of the residential and commercial buildings can be networked together to allow the consumer to access and operate with the real-time electricity price based energy management (RTEPEM) system. The loads are classified in two categories; (a) Critical load (CL) and (b) Non-critical load (NCL). Those appliances do not have store energy storable ability such as light (CFL, LED), fan, exhaust fan, hair dryer, television, external modem, vacuum cleaner, the sandwich maker are called critical load. Theses loads are controlled by the operator manually i.e the control actions of these appliances are free from the electricity prices and the feedback to control the desired parameters. Those appliances have the energy storable capacity are belongs to the NCL category of the load. The NCLs are also classified in two categories; (a) cycle based load (CBL) like air conditioner, refrigerator, and (b) deferrable load (DL), these appliance has large energy storage capacity such as electric geyser, coffee-maker, washing machine, laptop, cell phone, hybrid vehicle, and submersible and water purifier. The operating time of the deferrable load can be schedule from peak hours to regular hours i.e. high to low electricity price of the DC microgrid. The control actions of these appliances respond to electricity price of the DC microgrid to abstain the use of energy during a time interval of peak demand (i.e. high electricity price). The CBLs, such as air conditioner might extend their cycle time slightly ('OFF' time) to reduce the load on the DC microgrid during the peak hours, which is not observable to the consumer. Similarly, a refrigerator could defer the defrost cycle until off peak hours; The NCL appliances also consider the consumer controls to override the automated controls. For example consumer wants to switch 'ON' the geyser regardless the electricity sale price of microgird; he/she will be able to do so.

\section{E. Control Algorithm}

The control algorithm of the source and load scheduling is shown in Fig.3. The proposed scheme shifts the load to the cheapest power source and charges the ES during the regular hours (i.e. low electricity price). Additionally, it schedules the deferrable load from peak hours to the regular hours and operates the cycle based load with 'control cycle' during peak hours. The PV feed the maximum power to the DC microgrid irrespective to the electricity price at different time instant. The battery remains in the charging mode (act as load) if the PU electricity price is lower than the buying price of the $\mathrm{BB}$, the PV and PU balance the DC microgrid demand in this scenario. As the PU price is higher than the ES sale price, the ES starts discharging (act as source). Therefore the DC microgrid demand is balanced by PV and ES while the surplus power is feed in the PU. Additionally, if the demand is higher than the PV and ES capacity, the surplus demand is balanced by the PU (act as source).

The load management is responsible to control the cycle based load and deferrable load. When the electricity price of the DC microgrid is lower or equal to the set price for the appliances than the cycle based load (CBL) operate with the regular cycle and the deferrable load (DFL) remains in the switch 'ON' state with the control parameters. When the electricity price of the DC microgrid is higher than the set price for the appliances then the CBL operate with the control cycle (small 'ON' time) and the DFL remains in the switch 'OFF' state.

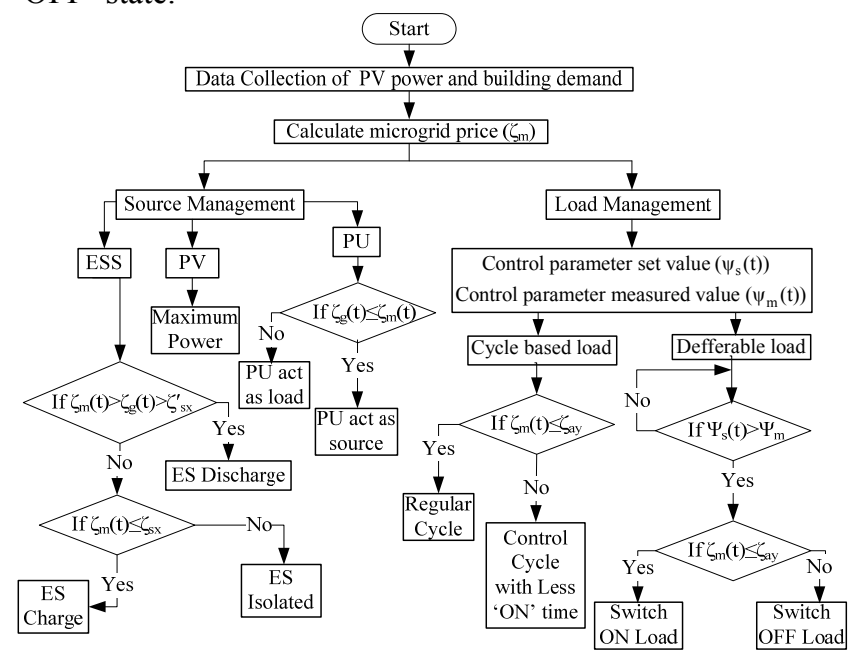

Fig. 3. Control algorithm for source and load scheduling system

\section{FORMULATION OF OPTIMIZED SCHEDULING OF MICROGRID}

The objective of the optimization is to minimize the electricity bill of the building in grid-connected mode and island mode. This objective can be achieved by minimization of the following defined objective function:

$$
F=\sum_{l=1}^{T} \zeta_{g}(l) \times P_{p u}(l) \times \tau_{h}+\sum_{l=1, m=1}^{T, N_{\text {OESA }}} \zeta_{m}(l) \times P_{m}(l) \times \tau_{h}
$$


where $F$ is the electricity bill for the building to be minimized, $\mathrm{T}$ is the scheduling horizon of the optimization, $\tau_{h}$ is the optimize time step $1 \mathrm{~min}, \zeta_{g}$ and $\zeta_{m}$ are the sale electricity price of PU and DC microgrid respectively, $P_{p u}$ is the power consumed from the PU, $P_{m}$ is the demand for other energy storage appliances (OESA). The first term in the objective function (12) express the cost of PU energy, the second term defines the cost of energy for OESAs smart power consumption.

The DC microgrid has no power source to produce the emission, when DC microgrid feeds the power to the grid, then it help to emission reduction. The optimization gives a solution to reduce the operation cost of DC microgrid by the utilization of the power of the cheaper source. The objective function given in (12) is subject to the constraints as follows:

The public utility power boundary constraint is as follows

$$
P_{p u l} \leq P_{p u}(t) \leq P_{p u u} \quad \forall t \in T
$$

where $P_{p u l}$ and $P_{p u u}$ are the lower and upper boundary of public utility power respectively.

The electrical energy storage power boundary constraint is as follows

$$
P_{\text {eesl }} \leq P_{\text {ees }}(t) \leq P_{\text {eesu }} \quad \forall t \in T
$$

where $P_{\text {eesl }}$ and $P_{\text {eesu }}$ are the lower and upper boundary of electrical energy storage power respectively.

The OESA power boundary constraint is as follows

$$
P_{\text {oesal }} \leq P_{\text {oesa }}(t) \leq P_{\text {oesau }} \quad \forall t \in T
$$

where $P_{\text {oesal }}$ and $P_{\text {oesau }}$ are the lower and upper boundary of OESA power respectively.

The DC bus power constraints of DC microgrid are as follows

$$
\sum_{k=1}^{n_{d g}} P_{d g k}(t)=\sum_{y=1}^{n_{a}} P_{L y}(t) \quad \forall t \in T
$$

The total energy requirement of deferrable load for the dayahead scheduling is to be met and can be expressed by an equality constraint

$$
\sum_{l=1 h}^{T_{d e f}} P_{d e f}(l) \times \tau_{h}=E_{d e f}
$$

where $T_{\text {def }}$ is the time that deferrable loads are available for to finish their task or to store the energy for future use, $P_{d e f}$ is the demand of deferrable loads, $E_{\text {def }}$ is the total energy forecast of deferrable loads for the day-ahead scheduling.

\section{Simulation Results}

The simulation performed in this paper are performed using a personal computer based on Intel ${ }^{\circledR}$, Core $^{\mathrm{TM}}$ i5-3320M CPU 2.6 GHz, 4 GB RAM with Microsoft Windows 7 Professional Edition 64-bit operating system. There are many variables in the simulation thus the computational load is very high and the simulation is not able to run in powergui with continuous simulation type with the given specification of the laptop. The powergui with discrete simulation type and backward Euler solver including with sample time of $0.1 \mathrm{sec}$ has been taking to alleviate the computational burden. In order to test the proposed real-time price based energy management system and its effectiveness, a public utility tied DC microgrid includes photovoltaic plant, lead-acid battery bank and hybrid car and other energy storage appliances like geyser, and laptop etc is applied. The PU AC-DC converter is responsible for the power balancing in the DC microgrid. The PV power collected from the PV plant for a typical day is plotted in Fig.4. The sizes of power source of the system are as follows: PV plant: 6kW, Battery Bank: 750 Ah and 24 Volt, Hybrid Car: $750 \mathrm{Ah}$ and 24 Volt

The PU prices and the PV generation are varying with time. It forces to divide the day in the six different scenarios (mode) to demonstrate the effectiveness of the proposed framework for the analysis.

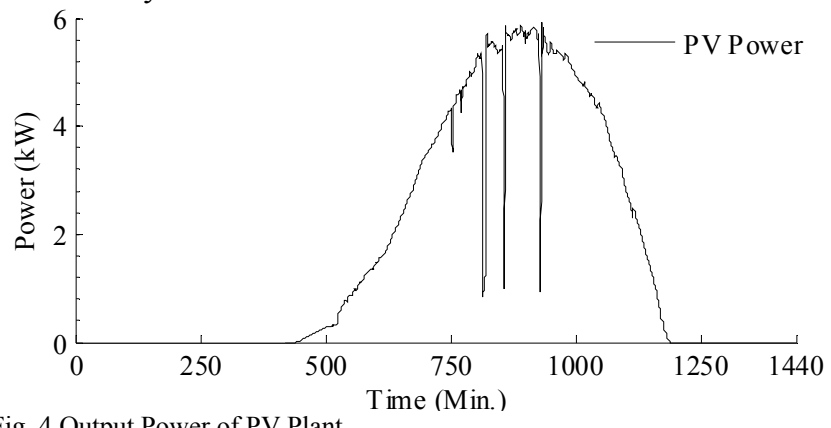

Fig. 4 Output Power of PV Plant

Mode $I-P U$ and ES as Source: During dark periods in the night, the PV power is zero and the DC microgrid is assumed to be connected with the PU. As a consequence between 00:00-3:24hrs, the PU prices are varying between Rs. 4.8 to 4.6 and BB prices are Rs. 4.39. Therefore BB is feeds rated power to the DC microgrid. Since the building demand is higher than the $\mathrm{BB}$ load sharing capacity; the alternative source is PU in this scenario. Henceforth during this time interval, the deficit load is provided by the PU. The power equation for this mode can be expressed as:

$\sum_{y=1}^{n_{a}} P_{L y}^{s}=\sum_{k=1}^{n_{e}} P_{d e k}^{s}(t)+P_{p u}^{s}(t)$

where $P_{L y}$ is the demand of $y^{\text {th }}$ appliance, $P_{d e k}$ and $P_{p u}$ are the power supplied by $k^{t h}$ ES and PU respectively, $n_{e}$ is the number of ES for $s$ scenario.

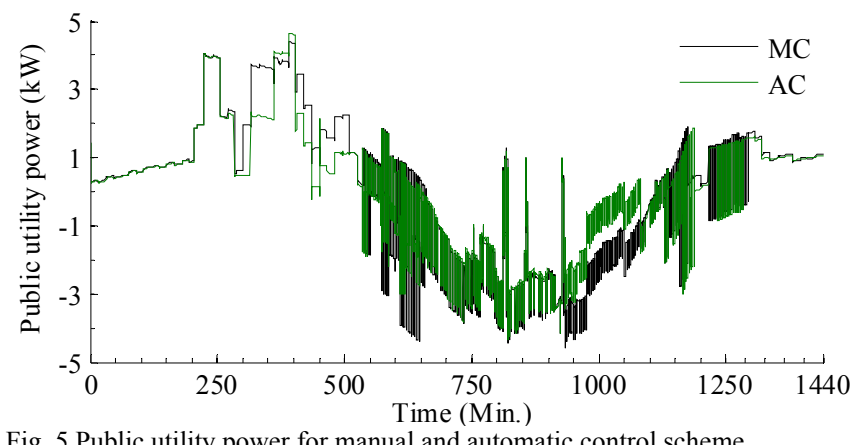

Fig. 5 Public utility power for manual and automatic control scheme

Mode II-PU as Source and ES as Load: During dark periods in the night, the PV system is not capable of producing electricity and the DC microgrid is assumed to be connected from the PU. As consequence between 03:44:4-:43hrs and 05:15- 
6:43hrs, the PU prices remain less than Rs. 3.82 , So the PU behaves as the source and ES (BB and HC) behaves as a load with the building appliances as shown in Fig.5. The BB and $\mathrm{HC}$ are charging with the rated power for a different instant of this mode as shown in Fig.6 and Fig.7 respectively.

The PU supplies the complete load of the DC microgrid and the DC microgrid prices remain same as PU prices during this scenario as shown in Fig.8. The power equation for this mode can be expressed as:

$$
P_{p u}^{s}(t)=\sum_{k=1}^{n_{e}} P_{d e k}^{s}(t)+P_{L y}^{s}
$$

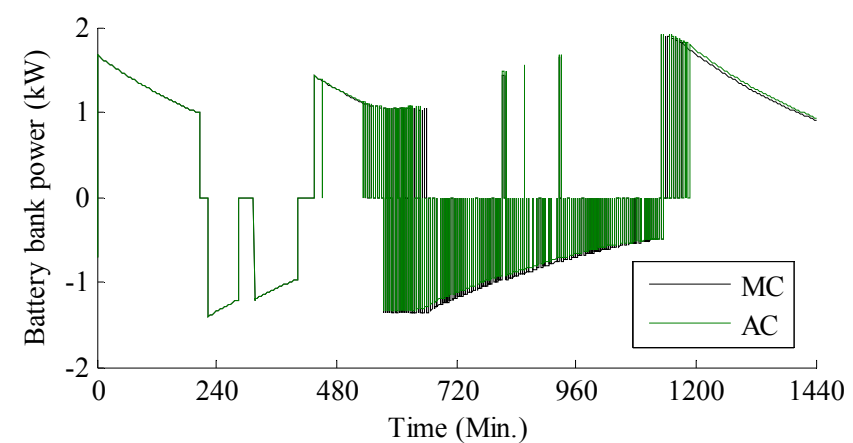

Fig. 6 Battery bank power for manual and automatic control scheme

Mode III-PV, PU and ES as Source: During early morning periods in the day, the PV system is generating small power and not able to supply the complete demand of the DC microgrid. Furthermore, PU prices are varying between Rs. 6.7-6.8 per $\mathrm{kWh}$ as shown in Fig.2. Further, the ES is discharging with its own rated capacity but the DC microgrid demand is higher than the submission of PV and ES during 08:54-09:14hrs and 08:58-09:05hrs with manual control and automatic control schemes for load respectively. The PU is a costly power source during this time interval, the PV and ES feed the rated power to the DC microgrid and only surplus load of the building is balanced by the PU in this time interval. The DC microgrid prices are the function of power sharing and the electricity sale prices of all power sources and varying between Rs.4.8-5.34/kWh and Rs.5.65-4.8/kWh with manual control and automatic control schemes of load respectively. The power expression for this mode can be expressed as:

$\sum_{y=1}^{n_{a}} P_{L y}^{s}(t)=\sum_{k=1}^{n_{d s}} P_{d s k}^{s}(t)+P_{p u}^{s}(t)$

where $n_{d s}$ is the number of distributed source (PV and ES), $P_{d s k}$ is the output power of $k^{\text {th }}$ source.

Mode IV $-P V$ and ES as Source: In the evening time of the day, the PV output power has been decreased from $1.89 \mathrm{~kW}$ $0.38 \mathrm{~kW}$ during 18:55-19:33hrs as shown in Fig.4. On the other hand, the PU price is remaining approximately Rs. $6.8 / \mathrm{kWh}$ during this time interval, it means the PU is the most costly power source in this time interval. So the system selects $\mathrm{BB}$ as a source at time instant 18:55hrs and 19:06hrs with manual control and automatic control scheme of load. Because $\mathrm{BB}$ is acting as a source, the load sharing capacity of the BB will decrease continuously as per (12). So the system selects $\mathrm{HC}$ as another source at time instant 19:23hrs and 19:24hrs with manual control and automatic control scheme. The DC microgrid prices are changing with the variation in the ratio of ES and PV power for manual control and automatic control scheme respectively. The power equation can be expressed as:

$\sum_{y=1}^{n_{a}} P_{L y}^{s}(t)=\sum_{k=1}^{n_{d s}} P_{d s k}^{s}(t)$

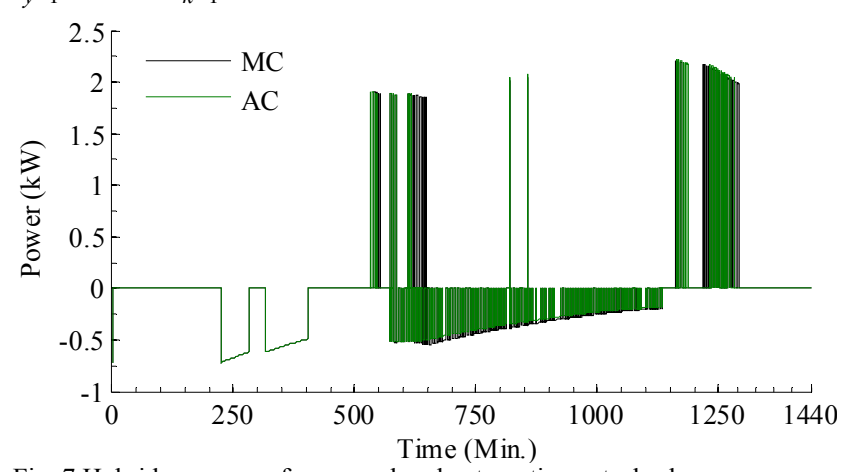

Fig. 7 Hybrid car power for manual and automatic control scheme

Mode $V-P U$ and ES as Load: As the day time increase, the PV generates the rated power. As a consequence, during 10:50-17:20hrs most of the time PV output power is greater than the sum of building demand and ES power so the DC microgrid prices remain fixed at Rs.3.82/kWh and load is supplied by the PV only. The surplus PV power is either stored in the ES or fed to the PU as per the variation in the PU prices as shown in Fig.5, Fig.6, and Fig.7. So the power expression for this mode can be expressed as:

$P_{p v}^{s}(t)=\sum_{y=1}^{n_{a}} P_{L y}^{s}(t)+\sum_{k=1}^{n_{e}} P_{e k}^{s}(t)+P_{p u}^{s}(t)$

where $P_{p v}$ is sum of PVs output power $s$ scenario.

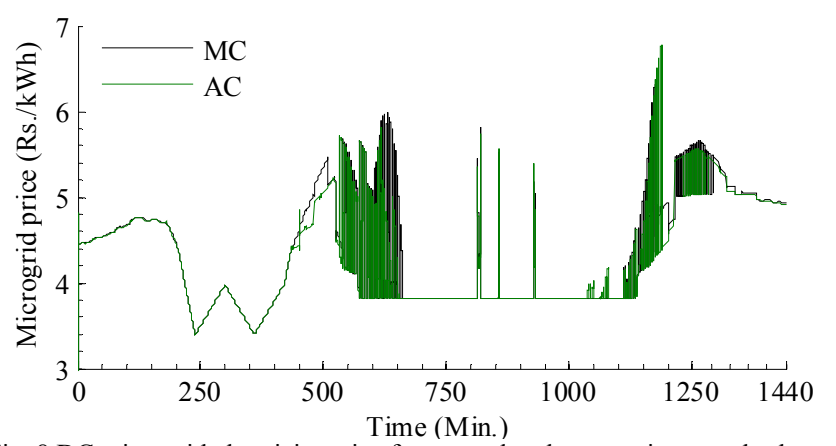

Fig. 8 DC microgrid electricity price for manual and automatic control scheme

Mode VI-ES as Source and PU as Load: During dark periods in the night, the PV power is zero and the DC microgrid is assumed to be connected from the PU. As consequence between 19:23-19:48hrs and 19:20-19:34hrs the time interval with automatic control scheme and manual control scheme, the PU prices are higher than the $\mathrm{BB}$ and $\mathrm{HC}$ electricity sale prices so the $\mathrm{BB}$ and $\mathrm{HC}$ act as a source and fed its rated power to the DC microgrid at different time instant of this mode. In this mode, when the load is less than the rated ES power (sum of BB and $\mathrm{HC}$ power), PU act as a load and 
consume the surplus power of the DC microgrid. During other time instants when the load is greater than the rated ES power, PU act as a source and feed surplus load of the building in order to balance the power in the DC microgrid. The power equation can be expressed as:

$$
P_{p u}^{s}(t)=\sum_{k=1}^{n_{e}} P_{d e k}^{s}(t)-\sum_{y=1}^{n_{a}} P_{L y}^{s}(t)
$$

The building demand reached at the highest level $3.81 \mathrm{~kW}$ during $16: 00-16: 40 \mathrm{hrs}$ and $16: 46-17: 30 \mathrm{hrs}$ with automatic control scheme and supplied by the PV at the lowest DC microgrid electricity prices Rs. 3.82 of the day. While the building demand with manual control scheme is highest at 08:16-8:30hrs and supplied by the PV and BB at the DC microgrid electricity prices Rs. 6.85-6.81 per kWh. During the PV connected mode, the building demand remains higher with automatic control scheme as compare to the manual control scheme while the building demand remain lower with the automatic control scheme as compare to the manual control scheme during the PV outage time interval as shown in Fig.9. It verifies that the building demand is shift from peak hour to the regular hours.

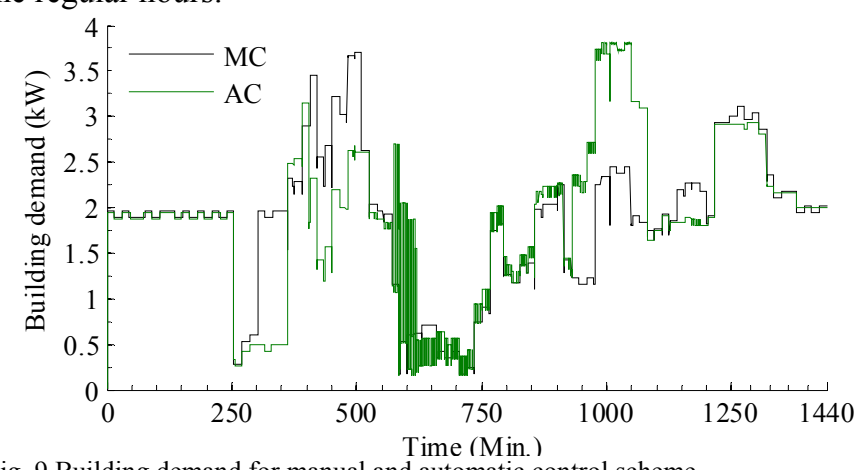

Fig. 9 Building demand for manual and automatic control scheme

\section{DisCUSSIONS}

It is clear that optimal scheduling of the NCL and the energy of $\mathrm{BB}, \mathrm{HC}$ including with public utility provides significant benefits to all involved. There are many challenges to be addresses when going to implement the system. One of them is the lack of the facility in the current BBs and EVs to give back energy to grid [23]. Protection issue at the interconnection point is also an important issue. Both issues discussed above are based on hardware available in the market and there cost is not standardised as well as on batteries, the manufacturer will not provide any warranty [24]. If consumers like to purchase low cost batteries, they may suffer the inconvenience to replace the batteries more frequently [25].

The building demand and energy sharing details of the power source such as $\mathrm{PV}, \mathrm{BB}, \mathrm{HC}$ and $\mathrm{PU}$ for manual control and automatic control schemes can be found in the Table 1. The PV generation remains same around $39 \mathrm{kWh}$ for both cases. The DC microgrid buy the approximately $19 \%$ lower power from the PU at the approximately $5.4 \%$ lower electricity price with the automatic control scheme as compare to manual control scheme. While the DC microgrid sales around $4.5 \%$ higher power to the $\mathrm{PU}$ at the $2.23 \%$ higher electricity price with the automatic control scheme as compare to manual control scheme.

The $\mathrm{BB}$ and $\mathrm{HC}$ received $11.21 \%$ and $15.36 \%$ profit in energy cost, when scheduled under the automatic control scheme as compare to the manual control scheme respectively. The automatic control scheme decrease the average cost of energy per kWh of the building electricity bill around $6.12 \%$ as compare to the manual control scheme.

Table 1 Description of energy and cost for the power sources and building

\begin{tabular}{|c|c|c|c|c|c|c|c|c|}
\hline \multicolumn{1}{|c|}{ Energy } & \multicolumn{5}{c|}{ Cost of Energy } \\
\hline Power & Buy & Buy & Sale & Sale & Buy & Buy & Sale & Sale \\
Source & MCL & ACL & MCL & ACL & MCL & ACL & MCL & ACL \\
\hline PV & 38.92 & 38.92 & - & - & 148.7 & 148.7 & - & - \\
\hline PU & 20.3 & 16.32 & 23.67 & 22.65 & 79.58 & 60.51 & 146.75 & 143.56 \\
\hline BB & 10.98 & 9.398 & 7.833 & 7.833 & 39.44 & 33.81 & 36.44 & 38.99 \\
\hline HC & 5.536 & 4.984 & 7.507 & 7.708 & 19.88 & 17.94 & 36.77 & 36.30 \\
\hline Building & - & - & 36.72 & 32.2 & - & - & 156.06 & 128.51 \\
\hline
\end{tabular}

*MCL manual control scheme of load, ACL automatic control scheme of load

\section{CONCLUSIONS}

The performance of the proposed real-time electricity price based energy management system for DC building with price based load and source scheduling has been tested. The source algorithm schedules the energy sale and purchase of hybrid car, and battery bank. The public utility energy exchange band is smaller with automatic control as compare to the manual control scheme. The load scheduling algorithm schedules the building demand from peak to regular hours. The proposed scheme offer significant financial benefits to building consumer and battery bank and hybrid car. Additionally system flexibility as well as peak demand reductions are also observed, which can aid the system in integrating additional intermittent renewable energy sources like photovoltaic.

\section{REFERENCES}

[1] T. Logenthiran, D. Srinivasan, A. M. Kambadkone, and H. N. Aung, "Multi agent system for real-time operation of a microgrid in real time digital simulator," IEEE Trans. Smart Grid, vol. 3, no. 2, pp. 925-933, Jun. 2012.

[2] H. Fakham, D. Lu, and B. Francois, "Power control design of a battery charger in a hybrid active pv generator for load following applications," IEEE trans. Ind. Electronic, vol. 58, no.1, pp.85-93, Jan. 2011.

[3] P. G. Barbosa, L. G. B. Rolim, E. H. Watanabe, and R. Hanitsch, "Control strategy for grid connected dc-ac converters with load power factor correction," in Proc. Inst. Elect. Eng.-Gen. Trans. Dist., vol. 145, no. 5, pp. 487-491, Sep. 1998.

[4] H. Yu, J. Pan, and A. Xiang, "A multi function grid connected pv system with reactive power compensation for the grid," Sol. Energy, vol. 79, no. 1, pp. 101-106, Jul. 2005

[5] M. Muratori, and G. Rizzoni, "Residential demand response: dynamic energy management and time-varying electricity pricing," IEEE Trans. on Power Syst., vol. 31, no. 2, pp. 1108-1117, Mar. 2015.

[6] P. Richardson, D. Flynn, and A. Keane, "Local versus centralized charging strategies for electric vehicles in low voltage distribution systems," IEEE Trans. Smart Grid, vol. 3, no. 2, pp.1020-1028, Jun. 2012.

[7] W. Burke, and D. Auslander, "Residential electricity auction with uniform pricing and cost constraints," North American Power Symposium, Starkville, USA, Oct. 2009. pp.1-6,

[8] R. A. Waraich, M. D. Galus, C. Dobler, M. Balmer, G. Andersson, and K. W. Axhausen, "Plug in hybrid electric vehicles and smart grids investigations based on a micro simulation," Transportation Research. Part C: Emerging Technologies, vol. 28, pp. 74-86, Mar. 2013. 
[9] H. K. Nguyen, and J. B. Song, "Optimal charging and discharging for multiple PHEVs with demand side management in vehicle to building," IEEE Jour. of Comm. Net., vol. 14, no. 6, pp. 662-671, Dec. 2012.

[10] Y. Weifeng, Z. Junhua, and W. Fushuan, "A hierarchical decomposition approach for coordinated dispatch of plug in electric vehicles," IEEE Trans. Power Syst., vol. 28, no. 3, pp. 2768-2778, Apr. 2013

[11] T. Ma, and O. Mohammed, "Real time plug in electric vehicles charging control for $\mathrm{V} 2 \mathrm{G}$ frequency regulation," in proc. IEEE $39^{\text {th }}$ Annual Conf. of the Ind. Electronics Society, IECON, Vienna, Nov. 2013, pp. 1197-1202,

[12] D. Wu, D. C. Alprantis, and L. Ying, "Load scheduling and dispatch for aggregators of plug in electric vehicles," IEEE Trans. Smart Grid, vol 3, no. 1, pp. 368-376, Sept. 2012.

[13] A. K. Basu, A. Bhattacharya, S. Chowdhury, and S. P. Chowdhury, "Planned scheduling for economic power sharing in a CHP based microgrid," IEEE Trans. on Power Del., vol. 27, no. 1, pp. 30-38, Feb. 2012.

[14] C. Koroneos, G. Xydis, and A. Polyzakis, "The optimization use of renewable energy sources the case of lemons island," Int. Jour. of Green Energy, vol. 10, no.8, pp. 860-875, May 2013.

[15] Y. Riffonneau, and S. Bacha, "Optimal power flow management for grid connected PV systems with batteries," IEEE Trans. Sustainable Energy, vol. 2, no. 3, July 2011 .

[16] W. Clark Gellings, "The Concept of Demand-Side Management for Electric Utilities", proceeding of the IEEE, vol. 73, no. 10, Oct 1985.

[17] A. H. M. Rad, V. W. S. Wong, J. Jatskevich, R. Schober, and A. L. Garcia, "Autonomous Demand-Side Management Based on GameTheoretic Energy Consumption Scheduling for the Future Smart Grid," IEEE Trans. Smart Grid, vol.1,no.3, pp. 320-331, Dec. 2010.

[18] S. D. Ramchurn, P. Vytelingum, A. Rogers, and N. Jennings, "AgentBased Control for Decentralised Demand Side Management in the Smart Grid," in Proc. The $10^{\text {th }}$ International Conf. on Autonomous Agents and Multi-agent System., vol.1, pp. 5-12, 2011.

[19] T. Logenthiran, D. Srinivasan, and T. Z. Shun, "Demand Side Management in Smart Grid Using Heuristic Optimization,” IEEE Trans. Smart Grid, vol. 3, no. 3, pp. 1244-1252, Sept. 2012.

[20] P. Palensky, and D. Dietrich, "Demand Side Management: Demand Response,Intelligent Energy Systems, and Smart Loads," IEEE Trans. Ind. Informatic. vol.7, no. 3, pp. 381-388, Aug. 2011.

[21] E. Matallanas, M. Castillo-Cagigal, A. Gutiérrez, F. Monasterio-Huelin, E. Caamaño-Martín, D. Masa, and , J. Jiménez-Leube, "Neural network controller for Active Demand-Side Management with PV energy in the residential sector," Applied Energy, vol. 91, no.1 pp. 90-97, Mar. 2012.

[22] K. S. Ng, C. S. Moo, Y. P. Chen, and Y. C. Hsieh, "Enhanced Coulomb counting method for estimating state-of-charge and state-of-health of lithium-ion batteries," Applied Energy,vol.86, no. 9, pp. 1506-1511, 2009.

[23] E. Sortomme, and M. A. El-Sharkawi, "Optimal scheduling of vehicleto-grid energy and ancillary services," IEEE Trans. Smart Grid, vol. 3, no. 1, pp. 351-359, Mar. 2012.

[24] E. Sortomme and M. A. El-Sharkawi, "Optimal charging strategies for unidirectional vehicle-to-grid," IEEE Trans. Smart Grid, vol. 2, no. 1, pp. 131-138, Dec. 2010

[25] B. K. Sovacool and R. F. Hirsh, "Beyond batteries: An examination of the benefits and barriers to plug-in hybrid electric vehicles (PHEVs) and a vehicle-to-grid transition," Energy Policy, vol.37, no.3, pp. 1095 1103, Mar. 2009

\section{ACKNOWLEDGEMENT}

Authors are thankful to Center for Electromechanics, University of Texas at Austin for providing data from "Pecan Street Project". Authors are also thankful to DST-UKIERI, BASE for financial support.

\section{BIOGRAPHIES}

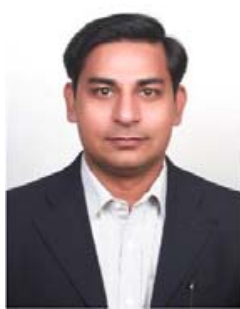

Rajeev Kumar Chauhan received M. Tech from National Institute of Technology Jalandhar, Punjab, India. Presently, he is pursuing Ph.D from School of Computing and Electrical Engineering, Indian Institute of Technology Mandi, India. Mr. Chauhan also received the Bhaskar Advanced Solar Energy (BASE-2014) fellowship from the Department of Science (DST) and Technology and Indo-US Science and Technology Forum (IUSSTF) and worked as Visiting Scientist in the Center for Electromechnics at University of Texas at Austin, US. His employment experience includes the Krishna Engineering College GZB, Galgotias College of Engineering and Technology Greater Noida, Roorkee Institute of Technology Rookee. His special field of interest included DC Micro-grid, SCADA System Industrial Automation and Control. He is the member of Institution of Engineers (India), IAENG Hong Kong and ICASIT.

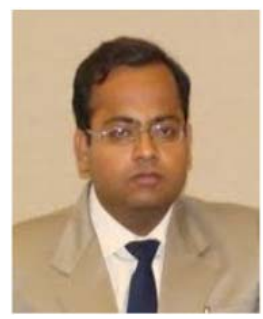

Bharat Singh Rajpurohit received M. Tech. from the Indian Institute of Technology Roorkee, India and $\mathrm{Ph} . \mathrm{D}$ from Indian Institute of Technology Kanpur, India. Presently, he is working as Associate Professor in the School of Computing and Electrical Engineering at Indian Institute of Technology Mandi, India. Dr. Rajpurohit received the BASE2015 fellowship from the DST and IUSSTF and working as Visiting Faculty in the Department of Electrical Engineering at the University of Wisconsin-Milwaukee, Wisconsin. His research interests include power electronics and grid integration of renewable energy sources. He is a member of ISTE and IEEE.

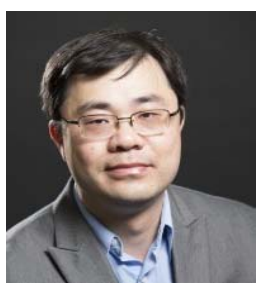

Lingfeng Wang received his $\mathrm{Ph} . \mathrm{D}$. degree from the Electrical and Computer Engineering Department at Texas A\&M University, College Station, Texas. He is currently an Associate Professor in the Department of Electrical Engineering at the University of Wisconsin-Milwaukee, Wisconsin. Previously, he was an Assistant Professor in the Department of Electrical Engineering and Computer Science at the University of Toledo, Ohio. He was also with California Independent System Operato (CAISO) for regional transmission planning. His major research interests include power system reliability and cybersecurity, renewable energy integration, intelligent and energy-efficient buildings, electric vehicles integration, and cyber-physical systems.

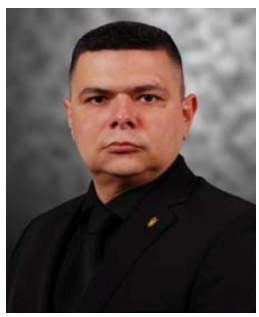

Francisco M. Gonzalez-Longatt is currently a Lecturer in Electrical Power System at Electrical Power System en School of Electronic, Electrical and Systems Engineering en Loughborough University. His academic qualifications include firs Class Electrical Engineering of Instituto Universitario Politécnico de la Fuerza Armada Nacional, Venezuela (1994), Master of Business Administration (Honors) of Universidad Bicentenaria de Aragua, Venezuela (1999) and PhD in Electrical Power Engineering from the Universidad Central de Venezuela (2008). He is former associate professor (1995-2009) and Chair (1999-2001) of the Department of Electrical Engineering of Universidad Nacional Politécnico de la Fuerza Armada Nacional, Venezuela (1995-2009). He is the author or editor of several books (Spanish and English) including "Power Factory Applications for Power System Analysis", Springer (2014 He is VicePresident of Venezuelan Wind Energy Association, Senior Member of the Institute of Electrical and Electronic Engineering (IEEE), member of The Institution of Engineering and Technology - The IET (UK) and member of International Council on Large Electric Systems -CIGRE. He received the professional recognition as FHEA - Fellow of the Higher Education Academy in January 2014. His research interest includes innovative (operation/control) schemes to optimize the performance of future energy systems. His research is or has been supported by Royal Society -UK. Two special research projects financially supported by the Royal Society deserve mention: "Smart Mult Terminal DC microgrids for autonomous Zero Net Energy Buildings" and "Exploring Beyond the Frontiers to Build a Smarter Grid (EBF2BSG)".

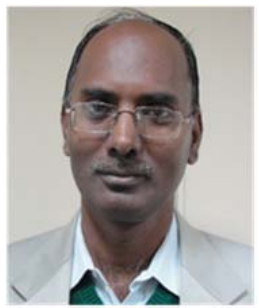

S. N. Singh received the Ph.D. degree in electrica engineering from the Indian Institute of Technology Kanpur, India, in 1995. He is currently a Professor with the Department of Electrical Engineering, Indian Institute of Technology Kanpur. His research interests include power system restructuring, FACTS, power system optimization and control, security analysis, and power system planning. Dr. Singh is a Fellow of the IETE, India, and the Institution of Engineers, India. 